\title{
Child categorization
}

\author{
Susan A. Gelman* and Meredith Meyer
}

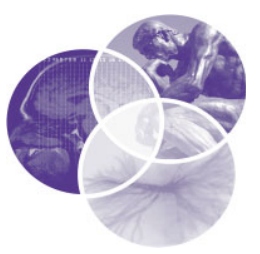

Categorization is a process that spans all of development, beginning in earliest infancy yet changing as children's knowledge and cognitive skills develop. In this review article, we address three core issues regarding childhood categorization. First, we discuss the extent to which early categories are rooted in perceptual similarity versus knowledge-enriched theories. We argue for a composite perspective in which categories are steeped in commonsense theories from a young age but also are informed by low-level similarity and associative learning cues. Second, we examine the role of language in early categorization. We review evidence to suggest that language is a powerful means of expressing, communicating, shaping, and supporting category knowledge. Finally, we consider categories in context. We discuss sources of variability and flexibility in children's categories, as well as the ways in which children's categories are used within larger knowledge systems (e.g., to form analogies, make inferences, or construct theories). Categorization is a process that is intrinsically tied to nearly all aspects of cognition, and its study provides insight into cognitive development, broadly construed. @ 2010 John Wiley \& Sons, Ltd. WIREs Cogn Sci 20112 95-105 DOI: 10.1002/wcs.96

\section{INTRODUCTION}

$\mathrm{O}$ ne of the primary means of organizing experience is to categorize, by treating discriminably different instances as alike. Categorization takes place when an infant separates out carrots from peas on her dinner plate; when a toddler says 'doggie' in the presence of dog pictures, toy dogs, and the family pet; when a teenager decides which classmates are 'emos', 'jocks', or 'nerds'; and when a chemist identifies the elements in a sample of rock. Infants and young children spontaneously categorize the world around them, in their unprompted sorting behaviors, ${ }^{1}$ sequential touching and objectexamination responses, ${ }^{2}$ and visual or auditory habituation patterns. ${ }^{3}$ Categorization is ubiquitous.

For adults and children alike, categories serve two primary functions ${ }^{4}$ : (1) they permit an efficient means of storing and retrieving information, such that we need not keep track of every individual item we encounter and (2) they promote inferences that extend knowledge beyond past experiences into the future, allowing us to make predictions that guide behavior. Understanding how items go together is foundational to adaptive action and problem solving.

*Correspondence to: gelman@umich.edu

Department of Psychology, University of Michigan, Ann Arbor, MI, USA

DOI: $10.1002 /$ wcs.96
Indeed, categorization or definitions are elements in tests of intellectual functioning such as the WAIS.

The study of categorization in children is of particular interest because categories are at the center of core debates regarding the nature of thought and the nature of development. Some of these debates include: is there qualitative change in development? To what extent are children's categories built up from low-level perceptual features versus informed by theories? Are there innate concepts? To what extent are categories constructed individually versus informed by cultural input? Does language guide or determine thought?

Examining children's categories is also revealing about children's developing belief systems across a wide range of domains, including naive biology (e.g., living vs non-living), social reasoning (classifying people by race, gender, personality traits, etc.), health (which foods are nutritious), and so forth. In all of these domains, cultural knowledge is embedded in categories. For example, how children reason about social relationships and in-groups versus outgroups is deeply informed by studying the nature and development of social categories, and is a timely topic of great current interest. ${ }^{5}$

This brief review is organized into three main sections. First, we address a central developmental debate regarding the basis of children's categorization, namely, the extent to which early categories are rooted in perceptual similarity versus knowledgeenriched theories. We argue for a composite view in 
which categories are steeped in commonsense theories from a young age but also are informed by low-level similarity and associative learning cues. Second, we examine the role of language in early categorization. We review evidence to suggest that language is a powerful means of expressing, communicating, shaping, and supporting category knowledge. Finally, we consider categories in context. We discuss sources of variability and flexibility in children's categories, making the point that children can reveal very different levels of competence depending on the task, content, and context. Additionally, we briefly examine how categories are used within larger knowledge systems (e.g., to form analogies, make inferences, or construct theories). Throughout, our focus is primarily on the period from roughly 2 years of age (when children have begun to demonstrate expressive language abilities) through elementary school, as this is a period of rapid growth in categorization. The period of infancy will be touched on only briefly, as it goes beyond the scope of the present article.

\section{WHAT IS THE BASIS OF CHILDREN'S CATEGORIES?}

A classic question for cognitive scientists is the degree to which developmental change can be characterized as continuous or discontinuous. This question has received much debate within the area of categorization. Certainly young children have much less factual knowledge than older children and adults (a quantitative difference), but the more controversial question is whether there is qualitative change in the structure, processes, or function of the categories formed at different points in development.

Over the past two decades, persistent debate has taken a somewhat different form: to what extent are children's categories based on available percepts alone and to what extent do they also make use of deeper sorts of information, such as causal and functional cues? Adults' categories do not reduce to perceptual features alone; instead, they reflect domain-specific knowledge and theories. ${ }^{6}$ For example, legless lizards look remarkably like snakes yet are classified as lizards based on the biological properties. More generally, features that participate in causal theories are weighted more heavily than features that are only associated with other features, and features that are causes are weighted more heavily than features that are effects. ${ }^{7}$ Some researchers have proposed that only adults possess theory-based categories, and that in contrast, young children are limited to considering salient perceptual features and linking them by means of associative learning processes. ${ }^{8}$ In contrast, others have argued that children's categories incorporate nonobvious, theory-based features from the start. ${ }^{9}$ In this section, we briefly review the evidence. The position we endorse is that children's categories make use of both theories and similarity, from early in development.

\section{Similarity and Associative Learning Models}

There are numerous 'minimalist' theories of early categorization, all resting on the idea that categorization reflects low-level cues that are present in the environment. Similarity-based models propose that categories are rooted in sensory and perceptual experiences that are analyzed by means of general-purpose processes alone (including associative learning, similarity assessment, and attentional weighting). ${ }^{10,11}$ Moreover, higher level conceptual processes are unnecessary to account for children's categorization skills. Thus, for example, if a preschool child classifies an item differently when it is labeled ('See this bird?') versus in a no-word control condition ('See this?'), this is because the word increases the similarity among the objects receiving the same label.

Featural similarity and associative learning appear to play important roles in children's category acquisition. For example, infants are sensitive to perceptual similarity when forming categories of animals and simple artifacts. ${ }^{12}$ Furthermore, associative learning strengthens the use of certain features over others. Thus, children's tendency to extend novel words on the basis of shape more than other features such as size, texture, or color, is strengthened by repeated experiences with contexts that highlight shape and associate same-shaped objects with a common label. ${ }^{13}$ Basic learning mechanisms enable the child to build up a rich (but atheoretical) network of correlated features, including labels. Infants as well as adults are sensitive to the statistical patterns characterizing cross-situational word and reference co-occurrences and can put this learning to use in learning correct mappings. ${ }^{14}$ This impressive capacity to track wordreferent associations across time is proposed as one possible mechanism to explain seemingly 'smart' word learning behaviors such as fast-mapping. ${ }^{15,16}$

\section{Theory-Based Models}

Theory-based models differ from similarity and associative learning models in proposing that children's categories are informed by factors beyond immediate sensory or perceptual cues and/or past associations. Theory-based models do not deny the importance of similarity and associative learning in children's representations, ${ }^{17}$ but propose that such features are predictive of 'deeper' similarities. Thus, for example, 
young children display a powerful bias to attend to shape, ${ }^{13}$ yet if shape is placed in competition with intended function (e.g., two objects have the same shape but different intended functions), then 3-year olds no longer display a shape bias. ${ }^{18}$ Similarly, even 2-year-olds categorize objects based on functional features that conflict with surface appearances, as long as the functions are plausible and distinctive. ${ }^{19,20}$ Likewise, 3- and 4-year olds categorize objects based on causal features, as long as the causal links are clearly and consistently demonstrated. ${ }^{21,22}$

Indeed, causal links can even override perceptual similarity, such that children provide two identical items with distinct labels, if their causal consequences differ. ${ }^{23}$ For example, if one block makes a machine light up but then an identical block has no effect, preschool children explain inconsistent effects by relabeling items, for example, 'It looks like a toma, but it's not. It's not really a toma at all' (Figure 1). The ability to link labels to causal effects is in place in early preschool ${ }^{24}$ but also become more sophisticated throughout the preschool years. ${ }^{22}$

Theory-based models also predict that categories will be sensitive to the domain in which objects appear. Thus, for example, preschoolers attend more to color in classifying foods than artifacts, because color is more predictive in the domain of food (e.g., carrots and parsnips can be distinguished by color, whereas shirts or cars can be any color). ${ }^{25}$ Likewise, 2- and 3-year olds attend more to texture in classifying animals than artifacts, because the presence of, for instance, fur versus feathers has important functional consequences. ${ }^{26} \mathrm{~A}$ recurring debate is whether these patterns are the result of associative learning patterns or reflect an appreciation for causal implications. ${ }^{13}$ Evidence for the latter is that domain-specific categorization can be cued by nonperceptual cues (namely, vignettes that make reference to relevant conceptual features, such as animacy), and that children show domain-specificity as early as 18-22 months of age, before they have acquired the associated vocabulary that is argued to be the basis of the distinction, on the associative learning account. ${ }^{26}$

One idea that has been proposed to account for children's use of nonobvious features in categorization is psychological essentialism. ${ }^{9,27}$ On this view, children and adults have a belief that certain categories are real (not human constructs), unchanging (not flexible), have a 'deeper' basis (not superficial), and hidden quality (essence) that causes observable features. This hidden quality is often not even specified or known, but rather is a 'placeholder' that is assumed to exist, even if the details are unknown. Essentialism posits that people have an abstract, skeletal set of expectations concerning how categories are structured and function, even before the particulars are filled in-a position that is consistent with other views of early cognition as consisting of broad general expectations. ${ }^{28}$ Thus, for example, children's categories are not an attempt to capture perceptual commonalities, but rather an expectation that any such surface commonality is a reflection of a deeper basis.

Essentialism entails treating a category as consisting of more than its surface features. This includes treating categories as: immutable, possessing sharp boundaries, possessing innate potential, and
FIG URE 1 | Approximately $50 \%$ of 4 - and 5-year olds spontaneously provided labels based on the causal features of the blocks rather than the perceptual features of the blocks (reprinted with permission from Ref 22. Copyright 2010 Wiley-Blackwell).

\begin{tabular}{|c|c|c|c|}
\hline $\begin{array}{l}\text { PHASE OF } \\
\text { EXPERIMENT }\end{array}$ & $\begin{array}{l}\text { CAUSAL EFFECTS } \\
\text { (Note: gray lines } \\
\text { indicate that the box } \\
\text { lights up when block } \\
\text { is placed on top.) }\end{array}$ & $\begin{array}{l}\text { EXPERIMENTER- } \\
\text { PROVIDED } \\
\text { LABELS }\end{array}$ & $\begin{array}{l}\text { CAUSAL- } \\
\text { BASED } \\
\text { LABELS }\end{array}$ \\
\hline Teaching phase & & $\begin{aligned} & =\text { Toma } \\
\Delta & =\text { Not-a-toma }\end{aligned}$ & \\
\hline Confirmation trial & & (none) & $\begin{aligned} \mathbf{\square} & =\text { Toma } \\
\Delta & =\text { Not-a-toma }\end{aligned}$ \\
\hline $\begin{array}{l}\text { Test trial: Light boxes } \\
\text { Both turn on }\end{array}$ & & (none) & $\begin{array}{l}\Delta=\text { Toma } \\
\Delta=\text { Toma }\end{array}$ \\
\hline $\begin{array}{l}\text { Test trial: Light boxes } \\
\text { Both stay off }\end{array}$ & & (none) & $\begin{array}{l}\Delta=\text { Not-a-toma } \\
\Delta=\text { Not-a-toma }\end{array}$ \\
\hline
\end{tabular}


fostering rich inductive inferences. ${ }^{9}$ Because children are dependent on expert knowledge to guide them to the appropriate classification (e.g., is a whale a fish or a mammal?), labels are an important source of information to children's categories. As young as 13 months of age, children make use of adult-supplied labels to modify category boundaries and draw novel inferences. For example, a child learning about a behavior of a typical bird is likely to infer that this property is also true of a perceptually similar birdlike dinosaur (a pterodactyl) but not of a perceptually atypical bird (a dodo). However, once an adult labels these items (the pterodactyl is labeled 'dinosaur', and the dodo is labeled 'bird'), children are more likely to extend the property to the other 'bird' (dodo) rather than the 'dinosaur' (Figure 2). ${ }^{29-31}$ Similarity-based theorists propose that these category-based inferences are due to similarity rather than essentialism. On their view, the label itself makes items from the same category more similar to one another (i.e., the auditory cues adjust the perceptual similarity relations among the items being considered ${ }^{11}$ ). In contrast, the theorybased position notes several aspects of the findings that the similarity-based model cannot accommodate. ${ }^{17}$

First, children do not display a general pattern in which all labels are privileged. Instead, they are sensitive to different kinds of words (e.g., nouns vs verbs; labels for animals vs artifacts), each linked to a different kind of concept (e.g., categories of objects vs events), reflecting children's sensitivity to the conceptually motivated use of the labels. ${ }^{17}$ Second, word-meanings incorporate a variety of abstract conceptual features, including 'intention', 'cause', and 'animacy', as well as sensory and perceptual features. ${ }^{32}$ Third, words refer to concepts, they do not merely associate to entities in the environment. A compelling demonstration of this point is that by 18 months of age, children who learn a novel word (e.g., 'whisk') in reference to a picture immediately
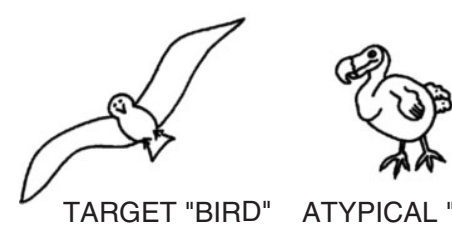

ATYPICAL "BIRD"

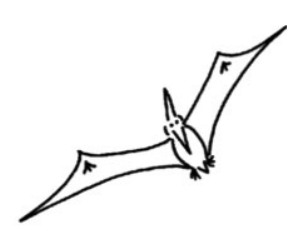

ATYPICAL (BIRDLIKE) "DINOSAUR"
FIGURE 2 | Preschool children who learn a new fact about the target bird are more likely to generalize that fact to an atypical bird than to a pterodactyl, indicating that the category label can be more important than outward appearances in children's inductive inferences (reprinted with permission from Ref 29. Copyright 1990 American Psychological Association). and preferentially extend the word to the actual object that the picture refers to Ref 33. If words were mere associations, then a word linked to a picture should extend mostly (or only) to other pictures.

A fourth and final point is that words acquire their meaning not only from their histories of cooccurrence with entities in the world, but also from the intricate linguistic and social systems of which they are a part. ${ }^{34,35}$ When mapping a meaning onto a word, children take into account morphological structure, grammatical context, and a host of social cues, including the speaker's eye-gaze, trustworthiness, and intentionality. Young children do not automatically map words onto co-occurring objects, and make use of information such as speaker intent. ${ }^{36}$ Further evidence for this point is that when social reasoning is impaired, as with autism spectrum disorder, children have difficulty correctly mapping a word onto its referent. ${ }^{37,38}$

\section{ROLE OF LANGUAGE IN CATEGORIZATION}

As is evident from several of the examples discussed above, the study of categorization is closely linked to the study of language. More generally, this point is apparent in at least three distinct ways. First, the words that children learn imply a vast set of underlying categories; with every utterance of $d o g$, run, or $u p$, children demonstrate that they have formed categories to which these words refer. Children's language, then, can provide us at least partial access to their categories and in the process shed light on the mechanisms that underlie category acquisition.

Second, language serves as an important vehicle for transmitting category-relevant information. Although much of the literature focuses on children as solitary learners, inventing or discovering categories on their own, ${ }^{39}$ we also know that categories are deeply informed by social and cultural input. ${ }^{40}$ The language provided by parents and knowledgeable others conveys information that extends well beyond the immediately perceptible world. ${ }^{41-43}$ Third, language provides a means of referring directly to categories in their entirety, as is seen in the use of abstract kind-referring noun phrases, or generics (e.g., Birds in Birds lay eggs). It is very difficult-perhaps impossible-to convey categories as a whole in the absence of language.

In this section, we discuss two interrelated questions that arise when considering the close link between language and categorization. First, we consider whether and how language may affect the categories children form. We then focus on generics both as a window on children's categories and a source of information to children regarding categories. 


\section{Effects of Language on Children's Categories}

The idea that language might exert a causal influence on categorization has experienced a recent resurgence, with focus on the Whorfian claim that different languages lead to different modes of thought. ${ }^{44}$ Even early on, language influences children's individuation and categorization of objects. $\mathrm{Xu}$ and colleagues find that labeling promotes children's ability to recognize objects as distinct entities through space and time. ${ }^{45}$ Further, well before any linguistic production of their own, infants are more likely to treat a set of identically labeled objects as similar (e.g., a series of rabbits) in comparison to the same set of objects presented without labels or with a non-linguistic sound, and to display a heightened novelty preference when exposed to an exemplar outside the original category (e.g., a pig). ${ }^{46}$

Labels also appear to license inductions beyond those afforded by visible perceptual features. For instance, infants expect objects that receive the same label to share nonobvious properties (such as a sound produced by an internal part), even if those objects are perceptually dissimilar ${ }^{31}$ (Figure 3). Further, infants even expect perceptually identical objects to have dissimilar nonobvious functions if they receive contrasting labels. ${ }^{32}$ The capacity for language to redirect attention beyond immediately perceptible attributes continues to affect older children's categories as well. For example, as noted in the previous section on theory-based models of categorization, providing a common label to perceptually dissimilar objects (e.g., a blackbird and a flamingo) invites preschool-aged children to generalize behaviors and traits across these instances, ${ }^{34}$ and providing a label to an ambiguous exemplar (e.g., calling a spoon-like key a 'spoon') promotes inferences that are consistent with the labeled category (e.g., using the object to eat). ${ }^{30}$

Thus, across development, language allows children to go beyond the perceptual in their categorical reasoning. In this way, labels appear to direct children to assume deeper similarities among the named instances and to make inferences that may not be consistent with immediately perceptual attributes. What are the mechanisms that underlie such effects? One possibility is that the act of labeling something implies the existence of an inferentially rich category to which that labeled entity belongs. Labels are argued to hold a privileged role in guiding category-based induction, licensing children to seek out deeper, kindbased similarities. ${ }^{9}$ This is not to say that language is the only means of constructing non-perceptual categories, but rather that children can be (and frequently are) alerted to deeper commonalities by a shared label. (a)
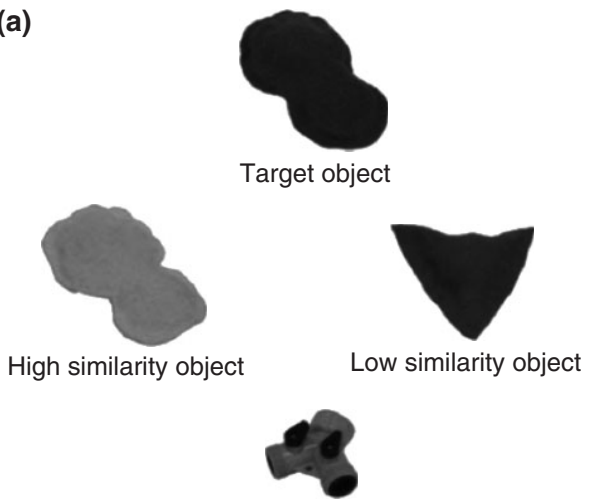

Dissimilar object

(b)

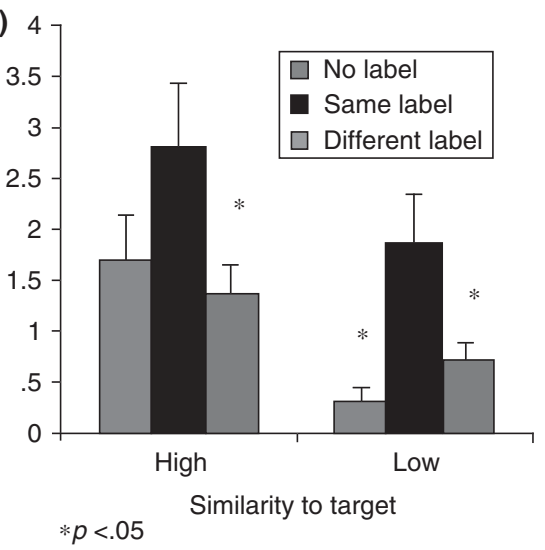

FI GURE 3 | (a) Sample item set. (b) Frequency with which 13-month olds perform target action (e.g., rattle) as a function of similarity to the target and same or different label from the target (reprinted with permission from Ref 31. Copyright 2004 Wiley-Blackwell).

Labeling may also have profound impact on children's judgments within the social world. For example, Gelman and Heyman ${ }^{47}$ found that 5- and 8 -year-old children were more likely to attribute stability to someone's behavior if it was presented with a noun label (e.g., Rose is a carrot-eater) as opposed to described in a predicate (e.g., Rose eats carrots whenever she can). Heyman ${ }^{48}$ demonstrated that this effect extends into children's judgments of academic skill as well; when elementary-schoolaged children heard a character described as a math whiz, for example, they attributed more stability and innateness to the character's math ability than if they heard that the character did the best on a math test. Relatedly, Cimpian et al. ${ }^{49}$ investigated how different ways of describing talent affected younger children's motivation to persevere in the face of failure. After hearing a fictional scenario in which talent was conveyed with a label (e.g., You are a good drawer) in comparison to a predicate (e.g., You did a good job drawing), 4-year-old children were less likely to report that they would want to continue on a drawing 
task after making a mistake. Further, hearing about ability predicated of a broad category as opposed to an individual has implications for children's motivations, suggesting that labels referring to categories are effective in conveying the idea that talent may be inherent to a category and hence more central and immutable. ${ }^{50}$ Taken together, this line of studies suggests that noun labels signal the existence of a wellstructured, inferentially rich category (e.g., carroteater, math whiz, good drawer), thereby providing stronger license than predicate-based information for attributions of stability and inherence of traits and behaviors. More generally, adults' labeling of social groups conveys that discrete kinds of people exist, with these groups united by internal and stable traits; in this way, children's sensitivity to adults' labeling styles shapes their processing of the social world. ${ }^{51}$

\section{Generic Nouns}

As noted earlier, generic noun phrases (hereafter generics) are linguistic forms that refer to categories rather than particular instances. ${ }^{52}$ For example, the generic birds in Birds lay eggs can be interpreted as 'the kind of thing known as a bird'; in contrast, a particular noun phrase refers to a specific instance or subset of the kind, as in My birds laid eggs. Generics express a unique type of information, indicating that a property is characteristic of the category but not necessarily universal or even statistically the most prevalent-the statement Birds lay eggs is considered true despite the fact that male and juvenile birds (which together clearly constitute the majority of all birds) do not lay eggs. ${ }^{53}$

Generics may be a uniquely effective means of expressing categorical knowledge consistent with essentialist reasoning. The idea that Birds lay eggs, for instance, may suggest not just that many birds lay eggs (i.e., that the property takes broad scope) but also that there is something inherent or essential to the bird category such that they lay eggs. The very fact that birds as a category receives the generic label thus allows for more inductive generalizations and judgments that go beyond any related to egg-laying; one might also expect a range of similar behaviors, properties, and traits to characterize birds as a group.

When considering the role of generics in children's essentialist beliefs about categories, one initial question is whether children are even sensitive to the means by which generics are expressed linguistically. A growing body of evidence strongly suggests that the answer is yes. Overt surface form differences between generic and particular noun phrases can be quite subtle (e.g., compare 'Birds lay eggs' to 'The birds lay eggs'), and there is no single unambiguous syntactic marker of generics. ${ }^{52}$ Nonetheless, children recognize many of the conventional linguistic devices used to express generics and can integrate their syntactic knowledge with considerations of semantic and pragmatic cues to arrive at adult-like interpretations. ${ }^{54,55}$

There is also support for the role of generics in promoting judgments consistent with essentialist reasoning. Preschool-aged children expect that properties predicated of generics are more central to a given noun category, ${ }^{56}$ and are more likely to use a property rather than overall similarity as a basis for categorization when told that the property is true of the generic (e.g., Keftas have humps) as opposed to an individual (e.g., This kefta has humps) ${ }^{57}$ (Figure 4). Children are also more likely to expect a property to have a more internal or causal basis after hearing the property expressed generically, and this effect holds for both social (e.g., gender) and non-social (e.g., animal) categories. ${ }^{58}$

Children's use of generics can reflect essentialism as well. Acquired early and by children in every language studied (even including home sign systems of deaf children), generics appear as a ubiquitous means of referring to categories. Notably, for both parents

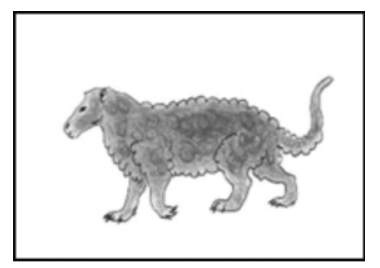

Sample target picture

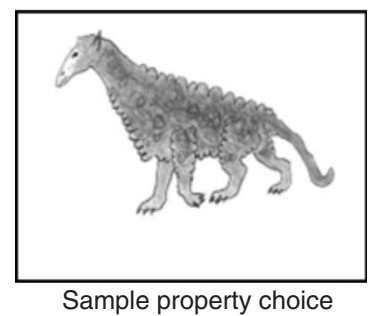

(woolly)

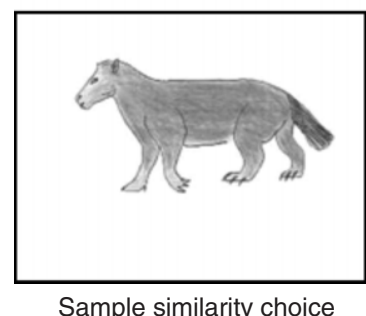

FIG URE 4 | Children who hear 'kevtas are woolly' are more likely to select the differently shaped woolly item as a kevta rather than the same-shaped non-woolly item (reprinted with permission from Ref 57. Copyright 2008 American Psychological Association). 
and children, generics are more often used to refer to natural kinds (e.g., animals) as opposed to artifacts (e.g., machines). ${ }^{59}$ This difference is consistent with the past research demonstrating that children expect natural kind categories to be more stable and inferentially rich $^{60}$ and provides indirect support for the role of generics in essentialist reasoning.

The exact nature of this role, however, is still unclear. One possibility is that parents' own tendency to use generics to refer to natural kinds is the sole source of differences in children, with any distinctions in kind-based reasoning across domains being a consequence of the input children receive. Such an explanation would be consistent with a unidirectional relationship between language and concept; without generics as a linguistic form, there would be no generic concept. We do not favor such a position, however. Although parents' generics may have the capacity to inform children about category structure, children's essentialist reasoning itself is an early-developed form of thinking. ${ }^{9}$

\section{CATEGORIES IN CONTEXT}

Categories are significant not only as representations in their own right, but also for how they link to other cognitive processes. Murphy refers to the representation of categories as 'a kind of mental glue', linking current perception to past experience; linking current experience to knowledge, theories, and imagination; enabling novel inferences; and mediating the relationship between language and reality. ${ }^{6}$ For example, the category 'tree' allows you to relate the tree in your yard to prior trees you have seen, to access your knowledge about trees, to generalize facts learned about one tree to other trees, and to interpret the English word 'tree' in a meaningful way. Thus, categories have implications for nearly every aspect of cognition. In this sense, categories can never be considered isolated representations, but are woven into the fabric of thought.

In this section, we consider two ways in which children's categories fit within a broader context. First, we outline ways in which the goals, context, and content of categories lead to variability and flexibility. Second, we consider how children combine categories into larger knowledge systems.

\section{Sources of Variability and Flexibility}

A powerful theme throughout the developmental categorization literature is that children's categories are highly varied and do not conform to a single, monolithic pattern, at any point in development. By preschool age (and often earlier), children can categorize based on shape, color, texture, number, gender, facial features, speech, musical tones, movement patterns, broad ontological information (such as animacy), nonobvious information (such as internal parts), and more. ${ }^{3}$ Children's categories include highly contextually sensitive groupings as well as broad, context-free groupings. They are both abstract and concrete. They reflect subtle statistical cues as well as powerful theories. They are linked to language and independent of language. They are highly flexible. In short, they display much of the range and flexibility of adult categories. ${ }^{61}$ Indeed, this variability partly accounts for the contrasting theoretical positions outlined earlier, as typically the selection of category and task differs, depending on whether one is interested in, for example, the role of causal knowledge or the influence of shape.

One way to think about the variation in children's categories is to consider that categorization entails choice: consciously or not, the categorizer chooses a perspective on the world. Any item could be categorized in a countless variety of ways, but at any given moment, the child focuses on no more than one or two. At times, this choice reflects a categorization goal: Do I strive for a rapid categorization even if it includes errors, or do I strive for the most thoughtful and informed categorization even if it slows me down? At other times, this choice reflects the category domain, context, or task at hand. Some have argued that this variability suggests that concepts do not exist as stable entities. ${ }^{62}$ Others propose that it is a mistake to pursue a single theory of concepts. ${ }^{63}$ Regardless of these broader theoretical implications, for current purposes, we note that variability in categorization is clearly systematic.

Some of the factors that influence children's categorization decisions involve the task itself. Being asked to sort objects leads preschool children to use different information than being asked to form inductive inferences. ${ }^{64}$ Framing the task as one that is teacher-led (pedagogical) leads 5- and 6-year-old children to make greater use of properties of the sample than when the task is framed as learner-driven (nonpedagogical). ${ }^{65}$ Implicit and explicit categorization tasks can lead to diverging results, though this depends somewhat on the age of the participant. ${ }^{66}$ Further, as detailed earlier, providing labels also exerts powerful effects on preschool children's categorization. ${ }^{16}$

Other factors concern the nature of the items being classified. Certainly, an array of simple geometric shapes will encourage a focus on perceptual features, whereas an array of animals will permit consideration of other features (such as genetic relatedness, environmental match). More generally, different 
domains (e.g., animals vs artifacts) encourage different modes of categorization. ${ }^{26,59,67}$ Pictures differ from objects in the kinds of categories they encourage, such that parent-child conversations about pictures focus relatively more on taxonomic categories, whereas parent-child conversations about objects focus relatively more on thematic relations. ${ }^{68}$ Children are also faster at processing functional relations as opposed to perceptual similarity relations for objects that can be manipulated (e.g., tools), but the reverse holds true for objects that cannot be manipulated (e.g., furniture). ${ }^{69}$

Currently, the findings of task and item effects are scattered, and there is not yet a coherent, integrative model for the factors that lead to different kinds of categorization at different points in development. This will be an important goal for future research.

\section{Categories in Larger Systems}

To this point, we have focused on categories as atomic entities; how does the child form a category of 'bird', 'cup', or 'whisk'? Yet individual categories can be compared, combined, and contrasted, in order to extend and develop one's knowledge. For adults, categories play an important role as components of larger knowledge systems. Evolutionary theory entails noting and testing hypothesized genetic relationships among categories that might at first appear unrelated (e.g., birds and dinosaurs). Analogical reasoning is the basis of much creative scientific thought, and requires forming new and unexpected comparisons among categories. ${ }^{70}$ Generalizing new facts often requires assessing the breadth of categories that instantiate that new fact (e.g., what is the likelihood that one's pet will contract a certain disease, given that both humans and squirrels do so?). These examples illustrate that much of the important work of categories is carried out in the context of larger systems in which they participate.

There is an extensive literature on how children combine categories to note taxonomic relations (e.g., birds and crocodiles are both animals), thematic relations (e.g., birds live in nests), and slot-filler relations (e.g., oatmeal and bacon are both breakfast foods). ${ }^{71}$ Although it was once believed that different relations were characteristic of distinct developmental stages, ${ }^{72}$ it is now recognized that category relations are highly flexible from as early as preschool age. Children and adults alike can classify based on taxonomic or thematic links, depending on the properties of the task and item. ${ }^{16,73,74}$

Children are also capable of comparing and contrasting categories, from preschool age. For example, as noted earlier, categories are elements in naive theories, and a category such as 'girl' differs importantly from a category such as 'rock' in that only the former is part of a theory of intentional action. ${ }^{75-77}$ However, the manner in which children combine categories changes with development. Theory change in childhood provides a potent example, for as children's theories change, the component categories are forced to change as well. Thus, for example, classification of what is 'alive' is influenced by changing theories of biology—as well as cultural and linguistic factors. ${ }^{78,79}$

Information gleaned from multiple categories also guides children's inductive inferences. ${ }^{80}$ For example, 8-year-old children are more likely to infer that all animals possess a property that they learn is true of goats and sheep than to infer that all animals possess a property that they learn is true of sheep. ${ }^{81}$ However, this capacity, too, undergoes marked developmental change. Adults draw more extensive inferences regarding properties they learn to be true of a diverse sample of categories than regarding properties they learn to be true of a homogeneous sample of categories (e.g., a property learned about a horse and a rabbit generalizes further than a property learned about a horse and a zebra; ${ }^{82}$ ). In contrast, children below middle childhood do not yet appreciate the importance of sample diversity and instead rely on characteristics of individual instances, such as their typicality (e.g., drawing more inferences from sparrows to other birds than from owls to other birds $\left.;^{80}\right)$. Interestingly, even much younger children can make use of category sampling information in certain kinds of learning contexts, though not when asked to evaluate competing sources of evidence. ${ }^{83}$

Categories are also fruitfully combined to generate comparisons, which permit extraction of more abstract properties than when considering just a single category. Thus, for example, when given individual pictures, children prefer to sort based on perceptual similarity (e.g., grouping an apple with a balloon rather than a banana), yet when provided with exemplars from two categories (apple and pear), thus permitting featural comparison, children now classify based on taxonomic relatedness (grouping the apple and pear with a banana more often than with a balloon) ${ }^{84} \mathrm{~A}$ similar effect can be found when children are asked to compare two categories as compared to two individual instances (e.g., 'Can you tell me some things that are the same about dogs and cats?' vs 'Can you tell me some things that are the same about this dog and this cat?'). ${ }^{85}$ Children are more apt to focus on superficial or spurious features when comparing individuals ('They are both brown'), and to focus on less obvious features when comparing categories ('They are both animals'). 
Although more research is needed to examine the developmental roots and consequences of these abilities, children's capacity to combine and compare categories illustrates that from an early age, categories play a role in all aspects of human cognition. ${ }^{6}$

\section{CONCLUSION}

Categorization is a component of a vast range of cognitive processes. As such, the study of categorization in children is linked to the study of cognitive development more broadly. In this review, we have highlighted the importance of domain-specific knowledge structures for categorization, the role of language in children's concepts, and the complexity, variability, and broader impact of categories for intelligent thought. Some exciting directions for the future include mapping out children's categories in particular domains (e.g., social cognition), determining the mechanisms that underlie category learning at different points in development, studying how sensitivity to cues in the input interact with children's causal understanding and naive theories, and determining how language interacts with these processes.

\section{ACKNOWLEDGEMENT}

Preparation of this article was supported by NICHD grant R01 HD36043 and NSF grant BCS-0817128 to Gelman.

\section{REFERENCES}

1. Sugarman S. Developmental changes in early representational intelligence: evidence from spatial classification strategies and related verbal expressions. Cogn Psychol 1981, 14:410-449.

2. Mandler JM. The Foundations of Mind: Origins of Conceptual Thought. New York: Oxford University Press; 2004.

3. Rakison DH, Oakes LM, eds. Early Concept and Category Development: Making Sense of the Blooming Buzzing Confusion. New York: Oxford University Press; 2003.

4. Smith EE. Concepts and categorization. In: Smith EE, Daniel O, eds. Thinking, Vol. 3. Cambridge, MA: MIT Press; 1995, 3-33.

5. Olson KR, Dweck CS. A blueprint for social cognitive development. Perspect Psychol Sci 2008, 3:193-202.

6. Murphy GL. The Big Book of Concepts. Cambridge: Cambridge University Press; 2002.

7. Ahn WK, Kim NS. The causal status effect in categorization: an overview. In: Medin DL, ed. The Psychology of Learning and Motivation, Vol. 40. San Diego, CA: Academic Press; 2000, 23-45.

8. Smith LB, Jones S, Landau B. Naming in young children: a dumb attentional mechanism? Cognition 1996, 60:143-171.

9. Gelman SA. The Essential Child: Origins of Essentialism in Everyday Thought. New York: Oxford University Press; 2003.

10. Rakison DH, Lupyan G. Developing object concepts in infancy: an associative learning perspective. Monogr Soc Res Child Dev 2008, 73:1-110.
11. Sloutsky VM. The role of similarity in the development of categorization. Trends Cogn Sci 2003, 7:246-251.

12. Quinn PC, Eimas PD. Perceptual cues that permit categorical differentiation of animal species by infants. J Exp Child Psychol 1996, 63:189-211.

13. Smith LB, Samuelson L. An attentional learning account of the shape bias: reply to Cimpian \& Markman (2005) and Booth, Waxman \& Huang (2005). Dev Psychol 2006, 42:1339-1343.

14. Smith LB, Yu C. Infants rapidly learn word-referent mappings via cross-situational statistics. Cognition 2008, 106:333-338.

15. Carey S. Conceptual Change in Childhood. Cambridge, MA: Bradford Books, MIT Press; 1985.

16. Markman EM. Categorization and Naming in Children: Problems of Induction. Cambridge, MA: MIT Press; 1989.

17. Waxman SR, Gelman SA. Early word-learning entails reference, not merely associations. Trends Cogn Sci 2009, 13:258-263.

18. Diesendruck G, Bloom P. How specific is the shape bias? Child Dev 2003, 74:168-178.

19. Kemler Nelson DG, Russell R, Duke N, Jones K. Twoyear-olds will name artifacts by their functions. Child Dev 2000, 71:1271-1288.

20. Ware EA, Booth AE. Form follows function: learning about function helps children learn about shape. Cogn Dev 2010, 25:124-137. 
21. Gopnik A, Sobel D. Detecting blickets: how young children use information about novel causal powers in categorization and induction. Child Dev 2000, 71:1205-1222.

22. Legare $\mathrm{CH}$, Gelman SA, Wellman HM. Inconsistency with prior knowledge triggers children's causal explanatory reasoning. Child Dev 2010, 81:929-944.

23. Opfer JE, Bulloch MJ. Causal relations drive young children's induction, naming, and categorization. Cognition 2007, 105:206-217.

24. Schulz L, Standing H, Bonawitz EB. Word, though, and deed: the role of object labels in children's inductive inferences and exploratory play. Dev Psychol 2008, 44:1266-1276.

25. Macario JF. Young children's use of color and classification: foods and canonically colored objects. Cogn Dev 1991, 6:17-46.

26. Booth AE, Waxman SR, Huang YT. Conceptual information permeates word learning in infancy. Dev Psychol 2005, 41:491-505.

27. Medin DL. Concepts and conceptual structure. Am Psychol 1989, 44:1469-1481.

28. Gelman R, Williams EM. Enabling constraints for cognitive development and learning: domain specificity and epigenesis. In: Damon W, ed. Handbook of Child Psychology, Vol. 2. New York: John Wiley \& Sons; 1998, 575-620.

29. Gelman SA, Coley JD. The importance of knowing a dodo is a bird: Categories and inferences in 2-year-old children. Dev Psychol 1990, 26:796-804.

30. Jaswal VK, Markman EM. Looks aren't everything: 24-month-olds' willingness to accept unexpected labels. J Cogn Dev 2007, 8:93-111.

31. Graham SA, Kilbreath CS, Welder AN. 13-Month-olds rely on shared labels and shape similarity for inductive inferences. Child Dev 2004, 75:409-427.

32. Dewar K, Xu F. Do early nouns refer to kinds or distinct shapes? Evidence from 10-month-old infants. Psychol Sci 2009, 20:252-257.

33. Preissler MA, Carey S. Do both pictures and words function as symbols for 18- and 24-month-old children? J Cogn Dev 2004, 5:185-212.

34. Baldwin DA, Meyer M. How inherently social is language?. In: Hoff E, Marilyn S, eds. Blackwell Handbook of Language Development. Malden, MA: Blackwell Publishing; 2007,, 87-106.

35. Keates J, Graham SA. Category markers or attributes: why do labels guide infants' inductive inferences? Psychol Sci 2008, 19:1287-1293.

36. Jaswal VK. Don't believe everything you hear: preschoolers' sensitivity to speaker intent in category induction. Child Dev 2004, 75:1871-1885.

37. Preissler MA, Carey S. What is the role of intentional inference in word learning? Evidence from autism. Cognition 2005, 97:B13-B23.
38. Baron-Cohen S, Baldwin DA, Crowson M. Do children with autism use the speaker's direction of gaze strategy to crack the code of language? Child Dev 1997, 68:48-57.

39. Piaget J. Genetic Epistemology. Trans. E. Duckworth. New York: Columbia University Press; 1970.

40. Vygotsky LS. Thought and Language. Cambridge MA: The MIT Press; 1962.

41. Koenig M, Harris P. The role of social cognition in early childhood. Trends Cogn Sci 2005, 9:457-459.

42. Gelman SA. Learning from others: children's construction of concepts. Annu Rev Psychol 2009, 60:115-140.

43. Callanan M, Braswell G. Parent child conversations about science and literacy: links between formal and informal learning. In: Bekerman Z, Nicholas B, Diana S-K, eds. Learning in Places: The Informal Education Reader. New York: Peter Lang Publishing, 123-137; 2006.

44. Gentner D, Goldin-Meadow S, eds. Language in Mind: Advances in the Study of Language and Thought. Cambridge, MA: MIT Press; 2003.

45. Xu F, Cote M, Baker A. Labeling guides object individuation in 12-month-old infants. Psychol Sci 2005, $16: 372-377$.

46. Fulkerson AL, Waxman SR. Words (but not tones) facilitate object categorization: evidence from 6- and 12-month-olds. Cognition 2007, 105:218-228.

47. Gelman SA, Heyman GD. Carrot-eaters and creaturebelievers: the effects of lexicalization on children's inferences about social categories. Psychol Sci 1999, 10:489-493.

48. Heyman GD. Talking about success: implications for achievement motivation. J Appl Dev Psychol 2008, 29:361-370.

49. Cimpian A, Arce HC, Markman EM, Dweck CS. Subtle linguistic cues affect children's motivation. Psychol Sci 2007, 18:314-316.

50. Cimpian A. The impact of generic language about ability on children's achievement motivation. Dev Psychol. In press.

51. Bigler RS, Liben LS. Developmental intergroup theory: explaining and reducing children's social stereotyping and prejudice. Curr Dir Psychol Sci 2007, 16:162-166.

52. Pelletier FJ, ed. In: Kinds, Things, and Stuff: Mass Terms and Generics. New York: Oxford University Press; 2009.

53. Leslie S. Generics and the structure of the mind. Philos Persp 2007, 21:375-403.

54. Cimpian A, Markman EM. Preschool children's use of cues to generic meaning. Cognition 2008, 107:19-53.

55. Gelman SA, Raman L. Preschool children use linguistic form class and pragmatic cues to interpret generics. Child Dev 2003, 74:308-325. 
56. Chambers CG, Graham SA, Turner JN. When hearsay trumps evidence: how generic language guides preschoolers' inferences about unfamiliar things. Lang Cogn Process 2008, 23:749-766.

57. Hollander MA, Gelman SA, Raman L. Generic language and judgments about category membership: can generics highlight properties as central? Lang Cogn Process 2008, 24:481-505.

58. Cimpian A, Markman EM. The generic/non-generic distinction influences how children interpret new information about social others. Child Dev. In press.

59. Brandone AC, Gelman SA. Differences in preschoolers' and adults' use of generics about novel animals and artifacts: a window onto a conceptual divide. Cognition 2009, 110:1-22.

60. Keil FC. Concepts, Kinds, and Cognitive Development. Cambridge, MA: MIT Press; 1989.

61. Gelman SA, Kalish CW. Conceptual development. In: Kuhn D, Siegler R, eds. Handbook of Child Psychology, Vol. 2: Cognition, Perception, and Language. New York: John Wiley \& Sons, 2006, 687-733.

62. Colunga E, Smith LB. Knowledge embedded in process: the self-organization of skilled noun learning. Dev Sci 2008, 11:195-203.

63. Machery E. Doing Without Concepts. New York: Oxford University Press; 2009.

64. Deák G, Bauer PJ. The dynamics of preschoolers' categorization choices. Child Dev 1996, 67:140-168.

65. Rhodes M, Gelman SA, Brickman D. Children's attention to sample composition in learning, teaching, and discovery. Dev Sci 2010, 13:421-429.

66. Baron AS, Banaji MR. The development of implicit attitudes: evidence of race evaluations from ages 6 to 10 and adulthood. Psych Sci 2006, 17:53-58.

67. Keil FC. The Birth and Nurturance of concepts by domains: the origins of concepts of living things. In: Hirschfeld L, Gelman SA, eds. Mapping the Mind: Domain Specificity in Cognition and Culture. New York: Cambridge University Press; 1994, 224-254.

68. Gelman SA, Chesnick RJ, Waxman SR. Mother-child conversations about pictures and objects: referring to categories and individuals. Cog Dev 2005, 76:1129-1143.

69. Kalénine S, Bonthoux F. Object manipulability affects children's and adults' conceptual processing. Psychon Bull Rev 2008, 15:667-672.

70. Gentner D, Holyoak KJ, Kokinov BN, eds. The Analogical Mind. Cambridge, MA: MIT Press; 2001.
71. Nelson K. The syntagmatic-paradigmatic shift revisited: a review of research and theory. Psych Bull 1977 , 84:93-116.

72. Inhelder B, Piaget J. The Early Growth of Logic in the Child: Classification and Seriation. London: Routledge and Kegan Paul; 1964.

73. Waxman SR, Namy L. Challenging the notion of thematic bias in young children. Dev Psychol 1997, 33:555-567.

74. Nguyen SP, Murphy GL. An apple is more than just a fruit: cross-classification in children's concepts. Child Dev 2003, 74:1783-1806.

75. Spelke E, Phillips A, Woodward A. Infants' knowledge of object motion and human action. In: Sperber D, Premack D, Premack A., eds. Causal Cognition: A Multidisciplinary Debate. New York: Oxford University Press, 1995, 44-78.

76. Kuhlmeier VA, Bloom P, Wynn K. Do 5-month-old infants see humans as material objects? Cognition 2004, 94:95-103.

77. Heyman GD, Phillips AT, Gelman SA. Children's reasoning about physics within and across ontological kinds. Cognition 2003, 89:43-61.

78. Carey S. The Child as Word Learner. In: Halle M, Bresnan J, Miller GA, eds. Linguistic Theory and Psychological Reality. Cambridge, MA: MIT Press; 1978.

79. Angorro FK, Waxman SR, Medin DL. Naming practices and the acquisition of key biological concepts: evidence from English and Indonesian. Psych Sci 2008, 19:314-319.

80. Rhodes M, Gelman SA, Brickman D. Developmental changes in the consideration of sample diversity in inductive reasoning. J Cog Dev 2008, 9:112-143.

81. López A, Gelman SA, Gutheil G, Smith E. The development of category-based induction. Child Dev 1992, 63:1070-1090.

82. Osherson DN, Smith EE, Ormond W, López A, Shafir E. Category-based induction. Psych Rev 1990, 97:185-200.

83. Xu F, Tenenbaum JB. Word learning as Bayesian inference. Psychol Rev 2007, 114:245-272.

84. Namy LL, Gentner D. Making a silk purse out of two sows' ears: young children's use of comparison in category learning. J Exp Psychol Gen 2002, 131:5-15.

85. Gelman SA, Raman L, Gentner D. Effects of language and similarity on comparison processing. Lang Learn Dev 2009, 5:147-171. 